\title{
MEMORIAL SOBRE A TRAJETÓRIA ESCOLAR BÁSICA DE NUBIA CRISTINA SOUZA NUNES
}

Nubia Cristina Souza Nunes ${ }^{1}$

Resumo: O presente texto trata do memorial sobre a trajetória escolar de Nubia Cristina Souza Nunes, ex-integrante do Programa Conexões de Saberes. Tem como objetivo apresentar os passos percorridos desde o início da educação básica até a entrada à UFPA e quais os principais entraves de estudantes das comunidades populares adentrarem o ensino superior público. A memória foi usada como principal referência para construção do material. Em seus resultados, apresenta os esforços individual e coletivo para que de fato a educação seja uma questão de direito e não de privilégio de poucos.

Dedico estas memórias ao autor da minha fé Jesus Cristo, que pela sua misericórdia me ajudou a transpor os muros da Universidade e a realizar um dos meus maiores sonhos: estudar na UFPA.

À mãezinha Jacyra Souza (in memóry ) presença constante em todas as minhas conquistas, que me amou, acreditou no meu potencial e me ensinou o caminho que deveria seguir.

Às minhas filhas, esposo e família pela paciência, auxílio financeiro e acima de tudo pelo amor que têm demonstrado por mim.

Segundo Severino (2002), o memorial deve retratar com segurança, fidelidade e tranqüilidade a trajetória real, que sempre é permeada de altos e baixos, de conquistas e perdas. Devendo ser relatada com autenticidade e criticamente assumida, nossa história de vida constituise nossa referência. É nessa perspectiva que descreverei as minhas vivências. Registrar minha história é uma experiência ímpar, espero que seja relevante para os leitores e sonhadores. É com muito orgulho que partilharei uma parte da minha vida com você, caro leitor.

Sou belenense, casada, acredito que nasci no coração de Deus, depois com a permissão Dele fui fruto de uma aventura entre meus pais biológicos. Atualmente estou no último semestre, faço parte do conexões, onde conheci pessoas maravilhosas e adquiri conhecimentos inovadores por meio das ações desenvolvidas pelo programa. Fui abençoada com aprovação no concurso público da SEDUC (Secretaria Estadual de Educação) como Técnica em Educação.

\footnotetext{
${ }^{1}$ Especialização pela Universidade Federal do Pará em Política de Gestão e Financiamento da Educação e em Sistema de Garantia dos Direitos da Criança e do Adolescente, Especialização em Educação Inclusiva pelo Centro Universitário de Mauá, e-mail: nubianunes@ufpa.br
}

Revista PET Interdisciplinar e Programa Conexões /UFPA On-line. Ed. Especial - 2017, BELÉM/ PA - ISSN 2447-097X 


\section{Minha infância querida...}

Fui criada por uma pessoa muito especial, Jacira Souza (avó materna) sendo ela minha verdadeira "mãe". Mamãe esforçou-se para me educar. Porque mesmo não tendo estudos, fazia questão de sonhar com um futuro brilhante para seus filhos, já que em sua concepção somente por meio da educação as pessoas poderiam desfrutar de uma vida melhor. Por isso caro leitor,quando referir-me à minha mãe, entenda que estarei falando dessa mulher maravilhosa. Ela ficou viúva cedo, criou seus cinco filhos (Nazaré Reis, Iracema, Izaura, Iraci e Antonio Souza), assim como alguns netos Max André, Marcio André, Handley e duas filhas de criação, eu e minha "irmã" Nivia Cristina. Teve uma vida de muitas lutas, trabalhou desde cedo na fábrica de Castanha e no Asilo Santo Antonio, aposentada, ganhando um pequeno salário precisou ser lavadeira para ajudar no sustento familiar. Eu ajudava a entregar as roupas nas casas dos patrões, "morria de vergonha, quando levava as cruzetas com roupas". Porque enquanto criança pensava ser vergonhoso minha mãe ser lavadeira. Entretanto hoje, percebo e valorizo o seu esforço e que valeu a pena todo o seu sacrifício para me criar dentro de suas possibilidades. Sou chorona porque fui criada com muito mimo esse fator foi mal interpretado por algumas pessoas que me julgaram incorretamente.

\section{Minha primeira escola...}

Iniciei meus estudos na Escola Estadual Dr. Mário Chermont onde conclui o ensino fundamental, recordo-me como se fosse hoje, acordava cedo, quase sempre era a primeira da fila, mamãe me levava todos os dias para escola, adorava a hora do "recreio", por causa da merenda e das brincadeiras. Segundo Abramovich(1983, p.77) “A memória situa-nos do ponto de vista tanto da história social quanto individual, somos marcados por acontecimentos que tiveram impacto eloqüência para que deles nos lembrássemos[...] o escritor registra aquilo que a si mais impressiona", de fato os acontecimentos decorrem a partir da organização de sociedade que temos, e suas peculiaridades. Na década de setenta, o sistema educacional extremamente tradicional com filas para entrada, questionário para ser decorado, o professor como detentor do saber, avaliação mensurável dentre outros fatores que caracterizam a pedagogia tradicional em que o professor era o sujeito principal do processo educacional em detrimento ao educando. 
Enquanto na pedagogia tecnicista o elemento principal era a organização racional dos meios, em que professor e aluno ficam em segundo plano. Tive dificuldades em matemática, porque criei medo da professora autoritária e que não dava vez nem voz aos educando, criando assim uma barreira na disciplina, resultando na reprovação na $6^{\mathrm{a}}$ série, foi minha primeira experiência negativa nos estudos.

Dessa forma, pensamos que a escola deve ser um espaço que promova o prazer, que possibilite o sonho, a esperança e a utopia de uma educação libertadora. Entretanto, quando falamos em educação libertadora nos reportamos às obras Freireanas, que significam interação, diálogo, respeito, autonomia, democratização escolar, agentes multiplicadores, liberdade de expressão dentre outros.

No ensino médio estudei na Escola Estadual Deodoro do Mendonça, passando por um teste de seleção para ser matriculada nessa escola. Lembro-me de alguns dias em que saía mais cedo de casa, porque ia andando para a escola que agora era um pouco distante de casa. Concluindo o ensino médio em 1988 em Administração, curso que escolhi sem ter noção do que seria na verdade. Ainda no terceiro ano, consegui um estágio remunerado na antiga Telepará,que foi uma grande ajuda para minha família.

Ao concluir os estudos, não me sentia preparada para enfrentar a "guerra" do vestibular. Concebia estudar na UFPA utopia, entretanto sonhava. Borelli (1981, p.21) concebe "O que alarga a vida de uma pessoa são os sonhos impossíveis". Acredito que foram justamente os sonhos que me fizeram viver e lutar por dias melhores. E foi objetivando a realização desse sonho impossível que lutei.

Meu primeiro emprego foi numa escola particular, onde trabalhei doze anos na secretaria, escola que foi extinta por má administração, durante esses anos "parei no tempo", não continuando os estudos para ingressar no ensino superior. Então, me casei em 1991, com Nelson Filho e tivemos três filhas, Talyane e as gêmeas Thamyres e Thalyélle. "são meus tesouros".

Estando desempregada, estudava somente nas revisões para o vestibular, porque não tinha condições de custear o ano inteiro de cursinho. Voltei a sonhar com a vaga na UFPA. As experiências na escola que trabalhei fizeram apaixonar-me pela área educacional me identificando com a Pedagogia, foram três tentativas sem sucesso, a cada resultado negativo, sentia-me "impotente e burra".

Revista PET Interdisciplinar e Programa Conexões /UFPA On-line. Ed. Especial - 2017, BELÉM/ PA - ISSN 2447-097X 
Surgiu a oportunidade de prestar serviço na secretaria do Centro Cristã Gomes, sendo uma ajuda no sustento familiar, que não me dava condições para pagar cursinho preparatório. Meu intuito era dar a alegria para minha mãe de passar no vestibular e proporcionar uma vida mais digna para ela e minha família.

\section{Enfim, a realização do sonho...}

No vestibular de 2005 consegui realizar meu sonho, transpus os muros da universidade, sendo aprovada em Pedagogia, o curso do meu coração. Era uma sexta-feira, acordei cedo, reservei dinheiro para ver o resultado pela internet indo com um amigo que fizera também a prova, pois não agüentaria esperar ouvir o resultado pelo rádio. Chegando a hora do resultado,acessamos a página da universidade, lemos primeiro o nome do Giovanni e logo depois o meu nome. As lágrimas rolaram em meu rosto como uma cachoeira, louvei ao Senhor pela vitória e o coração ah...pensei que iria sair pela boca. No caminho de volta para casa, parecíamos duas crianças correndo pelas ruas e sorrindo de tanta felicidade. Os estouros de fogos na cidade anunciavam uma das maiores festa do vestibular paraense, o dia do resultado da UFPA.

Ao chegarmos a casa todos já sabiam, não posso esquecer os olhares de alegria e emoção da minha família e da Vanessa, também não esquecerei meus sobrinhos que festejaram minha aprovação Marley André, Danilo Henrique. Meu marido estava trabalhando chegando somente à tarde, com os demais da família. Foi uma festa que jamais esquecerei. Lembro-me da marchinha tradicional do vestibular, que ao tocar anunciava a grande vitória de ser caloura da Federal, foi "Pai d'égua", nos primeiros dias pensei que estava sonhando.

Após ter presenciado minha vitória, mamãe adoeceu e partiu aos noventa anos, em janeiro de 2007. Considero esse, o momento mais difícil de toda a minha vida, foi como se tivessem arrancado um pedaço do meu coração, doeu muito. Porque sonhara em vê-la entregando meu diploma na formatura.Você que tem sua mãe ame-a e valorize-a, porque abaixo de Deus considero o maior amor que temos.Com o coração dilacerado pela partida inesperada quase cai em depressão,mas com a ajuda de Deus, da família, dos conexistas e coordenadoras estou superando a falta da minha "gata", era como a tratava.

Sinto-me privilegiada, por compor esse grupo maravilhoso e espero sirva de referencial aos acadêmicos que continuarão a história do Conexões de Saberes. Encerro esse memorial 
sonhando com a universalização da educação como direito, defendida por Arroyo (2004, p.80) "Poderemos sonhar com noites de formatura em alunas e alunos populares sairão carregando uma caixa de ferramentas refinadas para a sobrevivência e também para sua realização plena como seres humanos".

\section{Referências Bibliográficas}

ABRAMOVICH, Fanny.Estão mortas as fadas? Literatura Infantil e Prática Pedagógica.Petrópolis,RJ: Vozes, 1997

ARROYO, Miguel G.Imagens quebradas:trajetórias e tempos de alunos e mestres.Petrópolis.RJ;Vozes,2004.

BORELLI,Olga. Clarice Lispector: esboço para um possível retrato..Rio de Janeiro: Ed.Nova Fronteira ,1981.

FREIRE.Paulo. Pedagogia da Autonomia: Saberes necessários à prática educativa.36ª ed. São Paulo: Paz e Terra, 1996.

SEVERINO,Antonio,Joaquim.Metodologia do trabalho científico.22 ${ }^{a}$ ed.São Paulo: Cortez,2002. 